\title{
ANALISA DEFORMASI CRASH BOX DENGAN VARIASI DIAMETER DENGAN SIMULASI SOFTWARE ANSYS 14.5
}

\author{
Nanang Tawaf ${ }^{[1]}$, Asroni ${ }^{[2]}$ \\ Jurusan Teknik Mesin Universitas Samawa ${ }^{[1]}$ \\ Jl. Raya Sering Kerato Sumbawa Jl Yos Sudarso No 9, Sumbawa Besar 84313, NTB \\ Jurusan Teknik Mesin Universitas Muhammadiyah Metro ${ }^{[2]}$ \\ Jl. Ki Hjar Dewantara No. 116 Kota Metro Lampung \\ Email : asroni14@yahoo.com
}

\begin{abstract}
Abstrak
Perkembangan teknologi dan perkembangan sistem keamanan pada alat transportasi sangat diperlukan oleh industry otomotif. Berbicara mengenai alat transportasi maka tidak lepas dengan kemungkinan kecelakaan lalu lintas yang akan terjadi, tentunya hal ini merupakan sesuatu yang tidak diharapkan, sehingga para produsen alat transportasi selalu berpikir untuk memberikan solusi terhadap hal tersebut dengan cara menambahkan beberapa sistem keamanan pada produknya agar dapat meminimalisasi efek yang ditimbulkan akibat kecelakaan. Dengan variasi diameter crash box maka deformasi yang terjadi semakin besar, yaitu crash box I diameter $90 \mathrm{~mm}$, crash box II diameter $85 \mathrm{~mm}$, crash box III diameter $80 \mathrm{~mm}$, crash box IV diameter 75 mm, masing - masing memiliki deformasi sebesar $0.021075 \mathrm{~m}, 0.028341 \mathrm{~m}, 0.028616 \mathrm{~m}$ dan $0.034857 \mathrm{~m}$. Semakin berkurangnya rasio $(D / L)$ maka efisiensi perpindahannya semakin kecil sehingga deformasi plastis yang dihasilkan makin besar pula sehingga penyerapan energinya makin maksimal dan efek deselerasi nya makin menurun, efisiensi gaya tabrak makin menurun dikarenakan perbandingan gaya puncak dan gaya ratarata semakin kecil akibat pemadatan atau compaction yang terjadi akibat tumbukan hal ini berpengaruh terhadap meningkatnya efek deselerasi yang kurang menguntungkan. Semakin besar diameter crash box, maka luas permukaannya juga semakin besar sehingga momen inersia luasannya pun juga semakin besar, besarnya momen inersia luasan berpengaruh terhadap nilai beban kritis yang dihasilkan, semakin besar momen inersia luasannya maka beban kritis yang diperlukan untuk mendeformasi crash box juga semakin besar karena beban kritis berbanding lurus dengan momen inersia luasan, besar beban kritis sendiri berpengaruh terhadap gaya yang diterima oleh crash box semakin besar beban kritis maka gaya awal yang diterima crash box untuk mengalami buckling pada dinding juga semakin besar, gaya awal inilah yang mengawali terjadinya lipatanlipatan pada dinding crash box.
\end{abstract}

Kata Kunci : Deformasi Crash Box, Energi regangan, Variasi Diameter

\section{PENDAHULUAN}

Perkembangan teknologi dan perkembangan sistem keamanan pada alat transportasi sangat diperlukan oleh industry otomotif. Berbicara mengenai alat transportasi maka tidak lepas dengan kemungkinan kecelakaan lalu lintas yang akan terjadi, tentunya hal ini merupakan sesuatu yang tidak diharapkan, sehingga para produsen alat transportasi selalu berpikir untuk memberikan solusi terhadap hal tersebut dengan cara menambahkan beberapa sistem keamanan pada produknya agar dapat meminimalisasi efek yang ditimbulkan akibat kecelakaan.

Dalam perkembangannya sistem keamanan yang diterapkan oleh para produsen kendaraan bermotor khususnya kendaraan roda empat, salah satunya adalah crash box, perangkat ini merupakan sistem keamanan pasif (passive safety system) dan merupakan salah satu bagian dari crashworty system yang digunakan untuk mengurangi tingkat keparahaan kecelakaan yang dialami penumpang atau bagian kendaraan yang vital seperti mesin akibat frontal crash.

Crash box yang diletakkan diantara bumper dan rangka pada bagian depan kendaraan merupakan bagian yang sangat penting sebagai penyerap energi impak dalam hal ini tabrakan depan frontal crash. Crash box ini diharapkan mengalami deformasi dengan menyerap energi impak sebelum mengenai bagian kendaraan yang lain seperti frame dan kabin sehingga deformasi yang terjadi dapat diminimalisasi.

Velmurugan and Muralikannan (2009) meneliti karakteristik penyerapan energi pada crash box dengan melakukan pengujian statik dan dinamik dari beberapa macam bentuk 


\section{Nanang Tawaf, Asroni}

penampang diantaranya lingkaran (circle), persegi (square), dan persegi panjang (rectangular) masing-masing crash box memiliki keliling, ketebalan, dan tinggi yang sama, hasil penelitian tersebut menunjukkan penyerapan energi spesifik pada penampang lingkaran (circle) lebih tinggi dari penampang persegi (square) dan persegi panjang (rectangular) sedangkan penampang persegi (square) lebih baik dari persegi panjang (rectangular).

Dari latar belakang inilah perlu dilakukan penelitian lebih lanjut mengenai besar pengaruh variasi diameter dan panjang crash box berpenampang lingkaran (circle) agar didapatkan penyerapan energi dan perilaku deformasi yang baik, hal ini dilakukan untuk mendukung hasil penelitian sebelumnya.

Tujuan yang ingin dicapai dalam penelitian ini adalah untuk mengetahui seberapa besar pengaruh variasi diameter crash box agar memiliki kemampuan menyerap energi dan perilaku deformasi yang baik pada pengujian (Dropped weight impact).

\section{TINJAUAN PUSTAKA}

\section{Collapsible Impact Energy Absorber Crash Box}

Crash box adalah salah satu jenis penyerap energi impak (Impact energy absorber) yang diletakkan diujung rangka depan kendaraan yang berfungsi sebagai penyerap energi impak akibat tabrakan pada bagian depan, pada saat terjadi tabrakan depan (frontal crash) crash box diharapkan dapat terdeformasi dengan menyerap energi tabrakan sebelum mengenai bagian yang dilindungi sehingga kerusakan pada rangka kabin utama dapat diminimalisasi dan penumpang dapat selamat. Energi yang diterima oleh crash box saat terjadi tabrakan diserap melalui deformasi plastis pada crash box itu sendiri, crash box menyerap energi impak dan mengurangi gaya maksimalnya diamana seluruh energi tabrakan didistribusikan secara merata dan besar gayanya tidak melebihi nilai yang diizinkan agar struktur yang lain terlindung dari kerusakan yang parah. Agar crash box dapat memproteksi struktur dengan baik maka desain crash box harus mengikuti kriteria sebagai berikut :

- Energi impak akibat tabrakan sebanyak mungkin harus dapat didistribusikan menjadi deformasi irreversible atau energi tabraknya diubah menjadi deformasi plastis.

- Crash box adalah peralatan sekali pakai sehingga harus mudah diproduksi dan biayanya rendah serta mudah pemasangan dan pelepasannya.

- Crash box harus cukup panjang agar jalur deformasi untuk penyerapan energi tabrakan semakin panjang pula, tetapi tidak mengambil terlalu banyak ruang pada bagian depan kendaraan.
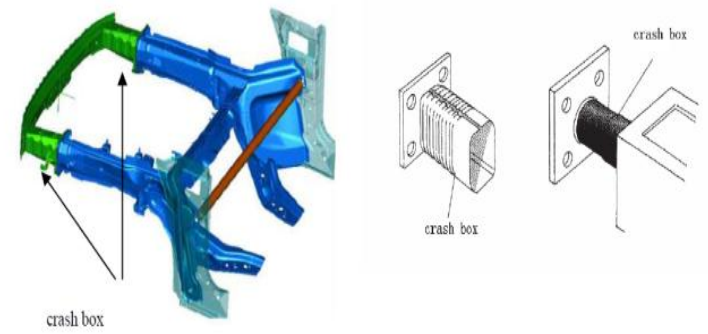

Gambar 1. Crash box pada struktur rangka kendaraan

Sumber :Liu Yanjie (2008)

\section{Tekuk (Buckling)}

Buckling merupakan suatu jenis dari kegagalan struktur yang terjadi pada struktur kolom atau struktur berbentuk tiang, hal ini terjadi akibat pembebanan secara aksial pada struktur tersebut, jika suatu tiang yang tipis diberi tekanan maka tiang tersebut akan membengkok dan terdefleksi secara lateral sehingga dapat dikatakan struktur tersebut mengalami buckling. Dengan bertambahnya beban aksial pada struktur kolom maka defleksi lateral juga akan bertambah dan pada akhirnya kolom akan benar-benar terdeformasi plastis. Ilustrasi buckling.
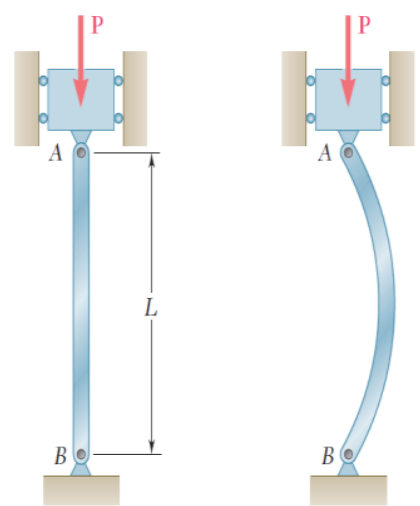

Gambar 2. Buckling pada struktur kolom Sumber : Beer, 2006: 635 


\section{Nanang Tawaf, Asroni}

Crash box merupakan salah satu jenis komponen yang berfungsi untuk menyerap energi kinetik akibat tabrakan dimana energi tersebut diubah kebentuk lain yaitu deformasi plastis pada struktur dengan bentuk tekukan tekukan yang disebut buckling, sehingga dengan adanya buckling pada crash boxtersebut energi kinetik akibat tabrakan yang diterima oleh kendaraan tidak langsung tersalur ke rangka utama yang akan menyebabkan kerusakan parah dan cidera pada penumpang.
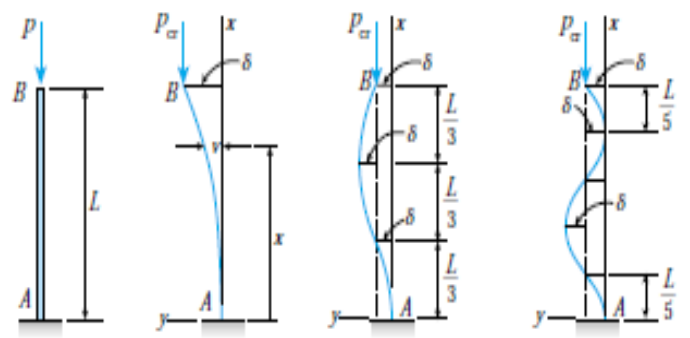

Gambar 3 Teori dasar buckling pada crash box Sumber : Gere, 2003 : 765

Perilaku struktur kolom yang ideal ketika diberi beban secara aksial ada tiga yaitu :

- Jika $P<P_{c r}$, maka struktur kolom dalam keadaan stabil dan setimbang dengan posisi tegak lurus.

- Jika $P=P_{c r}$, maka struktur kolom berada dalam kondisi netral ekuilibrium baik dalam posisi tegak atau sedikit membengkok.

- Jika $P>P_{c r}$, maka struktur kolom berada dalam kondisi ekulibrium yang tidak stabil pada keadaan tegak dan karena itu terjadi buckling.

$$
P_{c r}=\frac{\pi^{2} E I}{4 L^{2}}
$$

$P_{c r} \quad=$ Beban kritis $(N)$

$E \quad=$ Modulus Elastisitas $(P a)$

$I=$ Momen inersia penampang $\left(m^{4}\right)$

$L \quad=$ Panjang $\operatorname{kolom}(m)$

Bentuk dan jumlah tekukan pada

buckling berdsasarkan pada persaamaan tekuk $\cos k L=0$

Dengan persamaan kurva defleksi pada kolom yang tertekuk :

$$
v=\delta(1-\cos k x)
$$

Persamaan diatas dapat dipenuhi apabila :

$$
k L=\frac{n \pi}{2}
$$

dengan nilai $\mathrm{n}=1,3,5, \ldots$
Subtitusi nilai k ke dalam persamaan diatas dimana nilai $\mathrm{k}$ :

$$
k^{2}=\frac{P}{E I}
$$

Sehingga diperoleh persamaan beban kritis :

$$
P_{e r}=\frac{n^{2} \pi^{2} E I}{4 L^{2}}
$$

dengan nilai $\mathrm{n}=1,3,5, \ldots$

Selain itu diperoleh rumus kurva defleksi

bentuk ragam tekukan :

dengan nilai $\mathrm{n}=1,3,5, \ldots$

$$
v=\delta\left(1-\cos \frac{\pi x}{2 L}\right)
$$

\section{Energi Regangan}

Tumbukan dua buah benda akan menimbulkan konversi energy dari energi kinetik menjadi energi regangan (strain energy) pada material dengan mengabaikan perubahan energi ke bentuk lain. Energi regangan merupakan konsep dasar dalam mekanika terapan yang banyak digunakan untuk menentukan respon struktur terhadap beban statik dan dinamik.

Pada kondisi statik tanpa adanya efek dinamik dan inersia, pembebanan diterapkan secara perlahan-lahan sehingga beban bertambah dari nol ke harga maksimum. Pembebanan akan menyebabkan material mengalami pertambahan panjang (perpindahan akibat deformasi) hingga mencapai pertambahan panjang maksimum sesuai besar pembebanan. Fenomena ini umumnya disajikan dalam bentuk diagram beban-perpindahan (load-displacement diagrams).

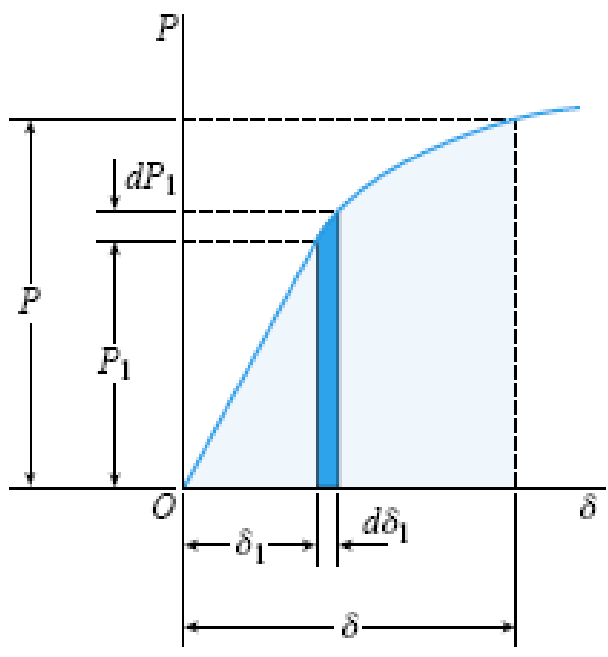

Gambar 4. Diagram beban-perpindahan Sumber : Gere, 2004 : 116 


\section{Nanang Tawaf, Asroni}

Berdasarkan tinjauan geometrik, usaha yang dilakukan oleh beban dalam rentang nilai $\mathrm{P}$ dan $\delta$ dinyatakan sebagai luas daerah dibawah kurva beban-perpindahan, sehingga dapat dirumuskan usaha total yang dilakukan oleh beban :

$$
\begin{aligned}
U & =\text { Energi regangan }(\mathrm{J}) \\
W & =\text { Usaha }(\mathrm{J}) \\
P & =\text { Beban }(\mathrm{N}) \\
\delta & =\text { Perpindahan }(\mathrm{m})
\end{aligned}
$$$$
\text { Dengan : }
$$

$$
U=W=\int_{0}^{\delta} P_{1} d \delta_{1}
$$

Energi regangan dibagi menjadi dua yakni energi regangan elastis dan energy regangan inelastis (gambar 5). Saat pembebanan dihilangkan perlahan-lahan material akan kembali kebentuk semula. Namun material tidak akan kembali ke bentuk semula bila batas elastic terlampaui.

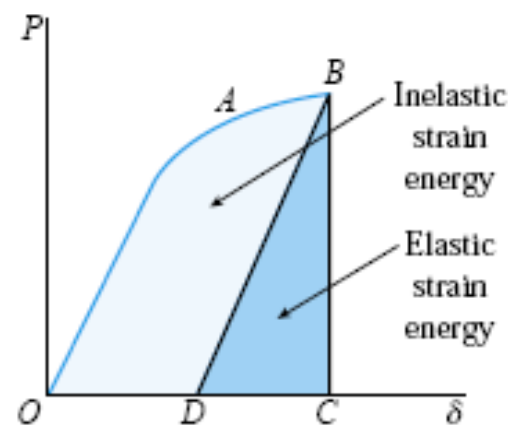

Gambar 5. Energi regangan elastis dan plastis

Sumber : Gere, $2004: 117$

Pada batas elastis, diagram beban perpindahan mengikuti garis linear (Gambar 5). Sehingga besar energi regangan yang tersimpan adalah sebesar luas daerah segitiga yang dibentuk oleh garis linear A dengan sumbu $x$. Besar energi regangan yang tersimpan sama dengan usaha yang dilakukan oleh beban.

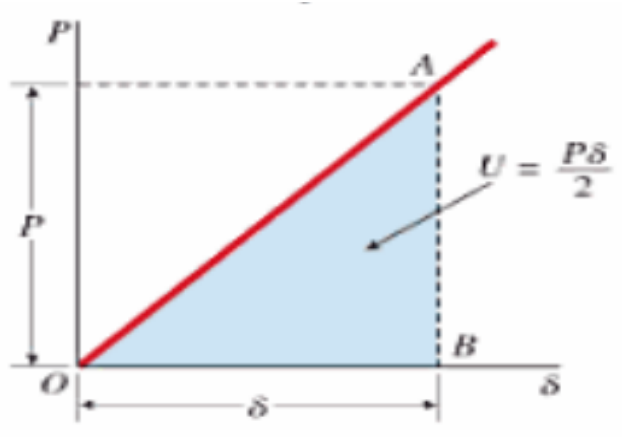

Gambar 6 Diagram beban-perpindahan elastic Sumber : Gere (2004 : 118)
Dan persamaan energi regangan dapat dirumuskan menjadi :

Dengan :

$$
\delta=\frac{P^{2} L}{2 E A}
$$

$P=$ Beban $(\mathrm{N})$

$L=$ Panjang material $(\mathrm{m})$

$E=$ Modulus elastisitas $(\mathrm{Pa})$

$A=$ Luas penampang $\left(\mathrm{m}^{2}\right)$

\section{Prosedur Perhitungan Metode Elemen Hingga}

Metode elemen hingga merupakan suatu prosedur numerik dengan konsep dasar adalah pembagian (diskretisasi) suatu kontinum menjadi elemen-elemen kecil yang berhingga dan memiliki bentuk geometri yang lebih sederhana dari kontinumnya yang disebut elemen hingga. Analisa metode elemen hingga dilakukan untuk mendapatkan suatu nilai pendekatan (bukan eksak) berdasarkan asumsi perpindahan atau asumsi tegangan atau dapat juga berdasarkan kombinasi keduanya.

1. Diskretisasi dan pemilihan elemen

Diskretisasi adalah proses membagi suatu struktur menjadi elemen-elemen kecil yang berhingga dan memiliki geometri yang lebih sederhana. Elemen-elemen ini berhubungan pada titik-titik simpul (node) membentuk rangkaian yang secara bersama dan keseluruhan mendekati bentuk struktur sebenarnya. Jadi bentuk geometri struktur yang kompleks dapat disederhanakan dengan diskretisasi untuk lebih mempermudah penganalisaan.

2. Memilih fungsi pendekatan

Variasi perpindahan pada suatu elemen didekati dengan fungsi interpolasi yang didasarkan pada harga simpul yang mengitari. Fungsi yang umum digunakan adalah polinomial. Pendekatan dengan fungsi interpolasi ini disebabkan sulitnya mencari jawaban tertutup, sehingga dipilih suatu bentuk jawaban, yaitu distribusi perpindahan yang merupakan besaran yang tidak diketahui dengan memakai fungsi yang harus memenuhi hukum, prinsip dan syarat batas yang menjadi sifat persoalan.

3. Menurunkan persamaan matrik kekakuan Prinsip usaha virtual menghasilkan persamaan matrik kekakuan elemen, yang dinyatakan sebagai: 


\section{Nanang Tawaf, Asroni}

$$
[k]=\int[B]^{T}[C][B] d V
$$

Dengan:

$$
\begin{array}{ll}
{[k]} & =\text { matrik kekakuan elemen } \\
{[B]} & =\text { matrik konstitutive hubungan } \\
& \text { regangan-perpindahan } \\
{[C]} & =\text { matrik konstitutive hubungan } \\
& \text { tegangan-regangan } \\
\mathrm{V} & =\text { volume }
\end{array}
$$

4. Menghitung matrik beban total

Beban yang bekerja didefinisikan menjadi tiga macam, sehingga beban total adalah:

$$
F=Q_{N F}+Q_{B F}+Q_{T}
$$

Dimana:

$Q_{N F}=$ beban pada konsentrasi node

$Q_{B F}=$ beban akibat beban sendiri (body force)

$Q_{T}=$ beban traksi (surface traction)

5. Merakit elemen menjadi struktur

Perakitan persamaan elemen dibawa ke bentuk persamaan global. Prosesnya harus memenuhi sifat konvergen dan sifat sinambung, yaitu titik-titik yang semula bersebelahan harus tetap bersebelahan setelah elemen dikenai beban. Bentuk persamaan global elemen:

$$
[K]\{q\}=\{R\}
$$

Dimana:

$[K]=$ matrik sifat $/$ kekakuan elemen

$\{q\}=$ vektor perpindahan node

$\{R\}=$ matrik beban total

Setelah matrik kekakuan global diperoleh dan syarat-syarat batasnya dimasukkan maka perpindahan simpul (q) dapat dicari. Suatu syarat batasmemberikan informasi bagaimana struktur ditopang dalam ruang, dengan memasukkan nilai perpindahan yang telah ditetapkan sesuai kondisi pada struktur.

6. Mendapatkan perpindahan global

Persamaan global yang mendapatkan syarat batas merupakan sekumpulan persamaan linier yang dapat diselesaikan dengan cara eliminasi Gauss untuk mendapatkan besaranbesaran primer, yaitu $q_{1}, q_{2}, q_{3}, \ldots q_{n}$.

$$
\begin{aligned}
& k_{1.1} q_{1}+k_{1.2} q_{2}+\ldots+k_{1 . n} q_{n}=R_{1} \\
& k_{2.1} q_{1}+k_{2.2} q_{2}+\ldots+k_{2 . n} q_{n}=R_{2} \\
& \ldots \\
& k_{n .1} q_{1}+k_{n .2} q_{2}+\ldots+k_{n . n} q_{n}=R_{n}
\end{aligned}
$$

Persamaan diatas akan diselesaikan dengan cara eliminasi Gauss untuk mendapatkan besaran-besaran rimer yaitu $\mathrm{q}_{1}$, $\mathrm{q}_{2}, \mathrm{q}_{3}, \ldots \ldots \mathrm{q}_{\mathrm{n}}$.
7. Mendapatkan besaran sekunder dan interpretasi hasil

Dari besaran pertamanya yang berupa perpindahan, dapat dicari besaran sekunder yang berupa tegangan atau regangan, dengan menggunakan hubungan antar keduanya. Hubungan tegangan-regangan pada kondisi 3D daat dinyatakan dalam bentuk matrik sebagai berikut :

$$
\left\{\begin{array}{c}
\sigma_{x} \\
\sigma_{y} \\
\sigma_{z} \\
\tau_{x y} \\
\tau_{y z} \\
\tau_{z x}
\end{array}\right\}
$$$$
=\frac{E}{(1+v)(1-2 v)}\left[\begin{array}{ccccccc}
1-v & v & v & 0 & 0 & 0 \\
v & 1-v & v & 0 & 0 & 0 \\
v & v & 1-v & 0 & 0 & 0 \\
0 & 0 & 0 & \frac{1-2 v}{2} & 0 & 0 \\
0 & 0 & 0 & 0 & \frac{1-2 v}{2} & 0 \\
0 & 0 & 0 & 0 & \frac{1-2 v}{2}
\end{array}\right]\left\{\begin{array}{c}
\varepsilon_{x} \\
\varepsilon_{y} \\
\varepsilon_{z} \\
\gamma_{x y} \\
\gamma_{y z} \\
\gamma_{z x}
\end{array}\right\}
$$

Hubungan tegangan-regangan:

$$
\{\sigma\}=[C]\{\varepsilon\}
$$

Hubungan regangan-perpindahan:

$$
\{\varepsilon\}=[B]\{d\}
$$
sebagai:

Sehingga tegangan dapat dirumuskan

$$
\{\sigma\}=[C][\mathrm{B}]\{d\}
$$

Hasil akhir dari perhitungan dengan metode elemen hingga ini berupa harga distribusi tegangan yang akan ditampilkan di sepanjang struktur untuk dianalisa sesuai dengan rumusan masalah.

\section{Software ANSYS}

Software yang berbasis elemen hingga ini mempunyai kelebihan yaitu kemampuan untuk mendiskritisasi model dengan sangat halus, mamu bekerja dengan elemen lebih banyak dan menghasilkan output dengan ketelitian tinggi. ANSYS dapat digunakan untuk menganalisis antara lain: struktural, termal, elektris, magnetis, dan fluida.

Secara umum langkah-langkah analisis dengan menggunakan ANSYS dibagi menjadi tiga, yaitu :

\section{Preprocessing (Proses Awal)}

Tahap-tahap penting dalam

Preprocessing :

- Pemodelan geometri : disini dilakukan proses modeling geometri baik 1D, 2D maupun 3D.

- Pemilihan tipe elemen : digunakan untuk mendiskritisasikan model yang dibuat. 
- Material properties : input data material yang digunakan.

- Meshing : pembagian struktur menjadi elemen-elemen kecil/elemen diskrit.

2. Solution (Proses Solusi)

Tahap-tahap penting dalam Solution :

- Mendefinisikan analisis solusi yang dipakai (Analysis Type).

- Memasukkan kondisi batas (constrain).

- Menerapkan pembebanan.

- Penyelesaian (Solving).

3. General Postprocessing (Proses Pembacaan Hasil)

a. Plot Result

Dengan menggunakan contour plot akan tampak distribusi tegangan atau variabel lain pada model sehingga mudah dalam menginterpretasikan informasi yang disajikan. Disini model digambarkan dengan sebaran warna yang menunjukkan besarnya tegangan yang terjadi.

\section{b. List Result}

Hasil analisis dalam bentuk List Result berupa tabel yang memberikan informasi secara detil mengenai perindahan, tegangan dan regangan yang terjadi pad tiap node mauun elemennya.

\section{Animation}

Hasil analisa yang diperoleh juga ditampilkan dalam bentuk simulasi (animasi).

\section{METODOLOGI PENELITIAN}

Metode penelitian yang digunakan dalam peneltian ini adalah eksperimenal semu dengan simulasi komputer menggunakan software ANSYS 14.5 yangberbasis metode elemen hingga. Untuk mendapatkan informasi tambahan diperoleh melalui studi literatur dari buku pustaka, jurnal peneltian dan internet unuk memperoleh informasi tambahan yang diperlukan dalam penelitian.

\section{Variabel Penelitian}

1. Variabel Bebas

Variabel bebas adalah variabel yang besarnya ditentukan sebelum dilakukan penelitian dan tidak dipengaruhi oleh varabel lain. Variabel bebas dalam penelitian ini adalah diameter dan ketebalan crash box yang ditunjukkan pada tabel berikut :
Tabel 1. Variasi diameter crash box

\begin{tabular}{|c|c|c|c|c|}
\hline No & $\begin{array}{c}\text { Crash box } \\
1\end{array}$ & $\begin{array}{c}L \\
(\mathrm{~mm})\end{array}$ & $\begin{array}{c}\text { D1 } \\
(\mathrm{mm})\end{array}$ & $\begin{array}{c}\text { D2 } \\
(\mathrm{mm})\end{array}$ \\
\hline 1 & Silinder 1 & 50 & 100 & 80 \\
\hline 2 & Silinder 2 & 75 & 90 & 80 \\
\hline
\end{tabular}

\begin{tabular}{|c|c|c|c|c|}
\hline No & $\begin{array}{c}\text { Crash box } \\
2\end{array}$ & $\begin{array}{c}\mathrm{L} \\
(\mathrm{mm})\end{array}$ & $\begin{array}{c}\text { D1 } \\
(\mathrm{mm})\end{array}$ & $\begin{array}{c}\mathrm{D} 2 \\
(\mathrm{~mm})\end{array}$ \\
\hline 1 & Silinder 1 & 50 & 95 & 75 \\
\hline 2 & Silinder 2 & 75 & 85 & 75 \\
\hline
\end{tabular}

\begin{tabular}{|c|c|c|c|c|}
\hline No & $\begin{array}{c}\text { Crash box } \\
3\end{array}$ & $\begin{array}{c}\mathrm{L} \\
(\mathrm{mm})\end{array}$ & $\begin{array}{c}\mathrm{D} 1 \\
(\mathrm{~mm})\end{array}$ & $\begin{array}{c}\mathrm{D} 2 \\
(\mathrm{~mm})\end{array}$ \\
\hline 1 & Silinder 1 & 50 & 90 & 70 \\
\hline 2 & Silinder 2 & 75 & 80 & 70 \\
\hline
\end{tabular}

\begin{tabular}{|c|c|c|c|c|}
\hline No & $\begin{array}{c}\text { Crash box } \\
4\end{array}$ & $\begin{array}{c}\text { L } \\
(\mathrm{mm})\end{array}$ & $\begin{array}{c}\mathrm{D} 1 \\
(\mathrm{~mm})\end{array}$ & $\begin{array}{c}\mathrm{D} 2 \\
(\mathrm{~mm})\end{array}$ \\
\hline 1 & Silinder 1 & 50 & 85 & 65 \\
\hline 2 & Silinder 2 & 75 & 75 & 65 \\
\hline
\end{tabular}

2. Variabel Terikat

Variabel terikat adalah variabel yang besar nilainya tergantung oleh variabel bebas dan nilainya diperoleh setelah pelaksanaan penelitian. Dalam penelitian ini yang menjadi variabel terikat adalah energi regangan dan deformasi yang terjadi pada crash box akibat uji impak (Impactor).

3. Variabel Terkontrol

Variabel terkontrol adalah variabel yang besarnya dikendalikan atau dibuat tetap selama penelitian, yaitu :

a. Ketebalan crash box yang digunakan $5 \mathrm{~mm}$

b. Kecepatanimpactor $7,67 \mathrm{~m} / \mathrm{s}$.

c. Material crash box yang digunakan adalah AL7003-T7

d. Material impactor yang digunakan adalah structural Steel (steel 4340).

\section{Data Material dan Dimensi Spesimen}

Material crash box yang digunakan dalam penelitian ini berdasarkan penelitian sebelumnya (Wahyu Kurniawan). AL7003T7dengan material properties sebagai berikut : 
Tabel 2. Material properties crash box

\begin{tabular}{|l|l|}
\hline Aluminium AA7003-T7| & \\
\hline Density $\left(\mathrm{kg} / \mathrm{m}^{3}\right)$ & 2770 \\
\hline Poisson's Ratio & 0.33 \\
\hline Young Modulus (GPa) & 71 \\
\hline Yield Strength (MPa) & 247 \\
\hline UTS (MPa) & 291 \\
\hline Shear Modulus (GPa) & 26.692 \\
\hline Tangent Modulus (GPa) & 0.5 \\
\hline
\end{tabular}

Tabel 3. Material propertiesimpactor

\begin{tabular}{|l|l|}
\hline Structural Steel & \\
\hline Density $\left(\mathrm{kg} / \mathrm{m}^{3}\right)$ & 7850 \\
\hline Poisson's Ratio & 0.3 \\
\hline Modulus Elastisitas $(\mathrm{GPa})$ & 200 \\
\hline Yield Strength $(\mathrm{MPa})$ & 250 \\
\hline Shear Modulus $(\mathrm{GPa})$ & 76 \\
\hline Tangent Modulus $(\mathrm{GPa})$ & 1.45 \\
\hline
\end{tabular}

\section{PemodelanCrash Box}

Crash box dimodelkan secara tiga dimensi,, tahap awal proses simulasi dimulai dengan menggambar tiap bagian yang berperan penting dalam pengujian dropped weight impact, yaitu impactor, tumpuan dan crash box melalui fitur Design Modeler pada software ANSYS 13.0 yang selanjutnya di transfer pada analisis system explicit dynamics.

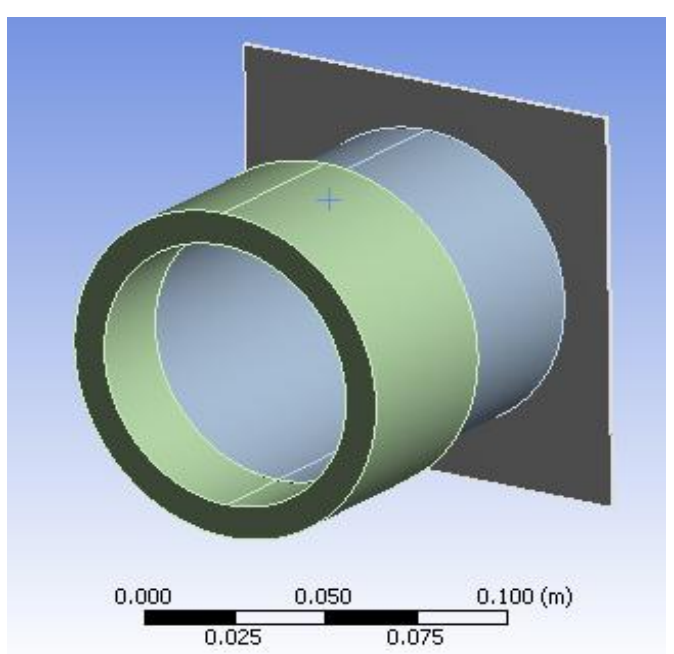

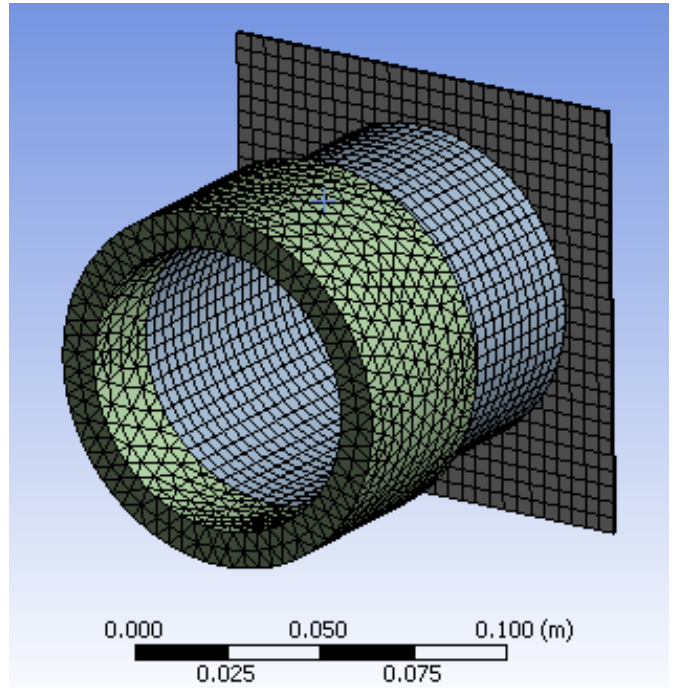

Gambar 9. Pemodelan dan Pola Meshing Crash $\operatorname{Box}\left(\mathrm{D}=100 \mathrm{~mm}, \mathrm{t}_{1}=10 \mathrm{~mm}, \mathrm{t}_{2}=5 \mathrm{~mm}\right)$

Hasil Dan Pembahasan

Tabel 4. Hasil Simulasi

\begin{tabular}{|c|c|c|c|c|c|}
\hline \multirow{2}{*}{$\begin{array}{l}\mathbf{N} \\
\mathbf{0}\end{array}$} & \multirow{2}{*}{$\begin{array}{c}\text { Cra } \\
\text { sh } \\
\text { Box }\end{array}$} & \multicolumn{2}{|c|}{$\begin{array}{c}\text { Dimensi } \\
(\mathbf{m m})\end{array}$} & \multirow{2}{*}{$\begin{array}{c}\text { Total } \\
\text { Deform } \\
\text { asi (m) }\end{array}$} & \multirow{2}{*}{$\begin{array}{c}\text { Strain } \\
\text { Intens } \\
\text { ity } \\
(\mathbf{m} / \mathbf{m})\end{array}$} \\
\hline & & $\begin{array}{c}\text { Silind } \\
\text { er } 1\end{array}$ & $\begin{array}{l}\text { Silind } \\
\text { er } 2\end{array}$ & & \\
\hline 1. & 1 & $\begin{array}{c}\mathrm{D}= \\
100, \mathrm{t} \\
=10, \\
\mathrm{~L}= \\
100\end{array}$ & $\begin{array}{c}\mathrm{D}= \\
90, \mathrm{t} \\
=5, \mathrm{~L} \\
=100\end{array}$ & $\begin{array}{c}0.02107 \\
5\end{array}$ & 1.053 \\
\hline 2. & 2 & $\begin{array}{c}\mathrm{D}= \\
95, \mathrm{t} \\
=10 \\
\mathrm{~L}= \\
100\end{array}$ & $\begin{array}{c}D= \\
85, \mathrm{t} \\
=5, \mathrm{~L} \\
=100\end{array}$ & $\begin{array}{c}0.02834 \\
1\end{array}$ & $\begin{array}{c}0.2909 \\
2\end{array}$ \\
\hline 3. & 3 & $\begin{array}{c}\mathrm{D}= \\
90, \mathrm{t} \\
=10, \\
\mathrm{~L}= \\
100\end{array}$ & $\begin{array}{c}\mathrm{D}= \\
80, \mathrm{t} \\
=5, \mathrm{~L} \\
=100\end{array}$ & $\begin{array}{c}0.02861 \\
6\end{array}$ & $\begin{array}{c}0.9514 \\
2\end{array}$ \\
\hline 4. & 4 & $\begin{array}{c}\mathrm{D}= \\
85, \mathrm{t} \\
=10 \\
\mathrm{~L}= \\
100\end{array}$ & $\begin{array}{c}D= \\
75, \mathrm{t} \\
=5, \mathrm{~L} \\
=100\end{array}$ & $\begin{array}{c}0.03485 \\
7\end{array}$ & $\begin{array}{c}0.5453 \\
4\end{array}$ \\
\hline
\end{tabular}

Tahap berikutnya adalah memasukkan data material tiap-tiap bagian yaitu structural steel untuk impactor dan fixedsupport dan AISI 1340 Steel, untuk crash box, crash box dimodelkan secara bilinear isotropic hardening sedangkan impactor dan fixedsupport dimodelkan sebagai material rigid. Kemudian 


\section{Nanang Tawaf, Asroni}

dilakukan proses meshing, yaitu proses membagi benda kerja dalam penelitian ini yaitu, impactor,crash box, dan fixedsupport menjadi elemen-elemen yang kecil. Semakin kecil elemen yang dibentuk maka semakin banyak pula persamaan yang harus diselesaikan oleh software, sehingga beban computer akan semakin besar namun nantinya hasil yang diperoleh juga akan semakin akurat.

Pada software ANSYS 14.5 meshing dapat dilakukan dengan dua cara yaitu manual dan otomatis, meshing secara manual adalah dengan mendiskritisasikan elemen yang akan dibentuk dengan input tipe, ukuran dan jumlah elemen sesuai yang diinginkan. Sedangkan meshing secara otomatis dengan memilih tipe elemen untuk ukuran dan jumlah elemen yang ditentukan secara otomatis oleh software. Dalam hal ini ANSYS akan menentukan sendiri secara otomatis berdasarkan pemodelan benda kerja dan spesifikasi computer yang dipakai. Dalam penelitian ini digunakan meshing secara otomatis dengan jenis elemen explicit, tipe elemen quadrilateral.
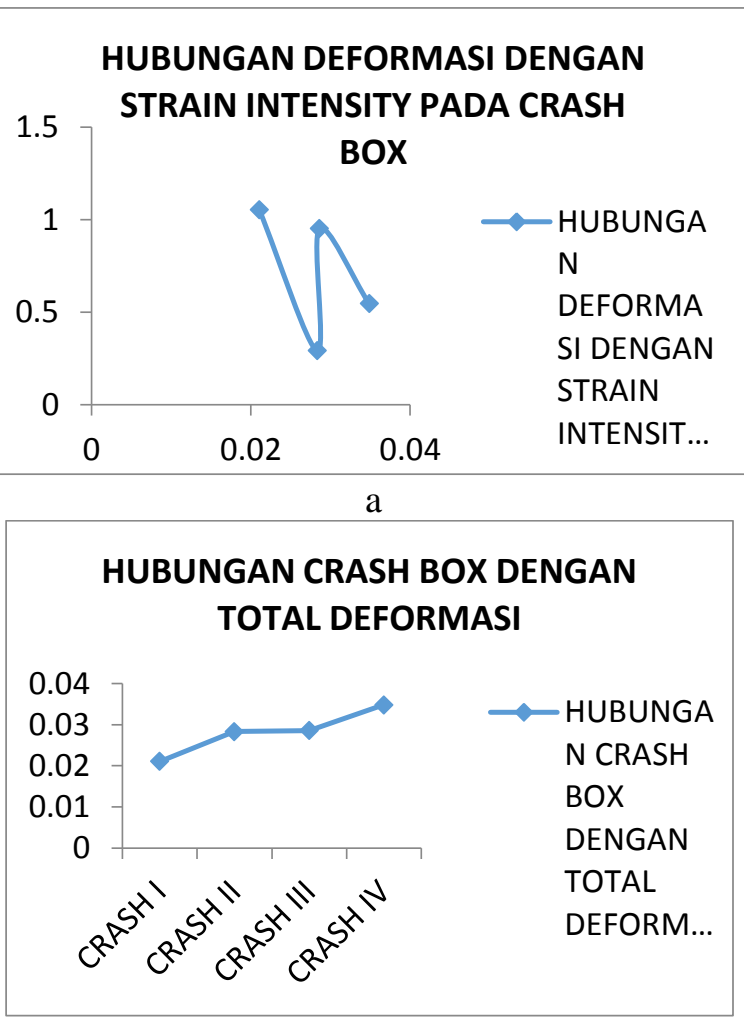

b

Dari grafik hubungan jenis crash box dengan total deformasi didapatkan nilai deformasi yang terbesar terjadi pada crash box IV dengan diameter silinder $75 \mathrm{~mm}$, sedangkan nilai deformasi terkecil terjadi pada crash box I dengan diameter silinder $90 \mathrm{~mm}$. Dari gambar diatas juga terlihat adanya peningkatan deformasi dari crash box I ke crash box II yaitu dari 0,021075 m menjadi 0,028341 $\mathrm{m}$ hal ini disebabkan oleh semakin besar diameter silinder pada crash box atau bidang kontak dengan impaktor maka nilai deformasi mengalami peningkatan. Kemudian nilai deformasi crash box II cenderung linear atau mengalami peningkatan yang tidak besar ke crash box III. Dan ini memberikan pengertian bahwa semakin kecil diameter crash box dengan bermaterial dasar berupa AL7003-T7 maka deformasi yang terjadi semakin besar.

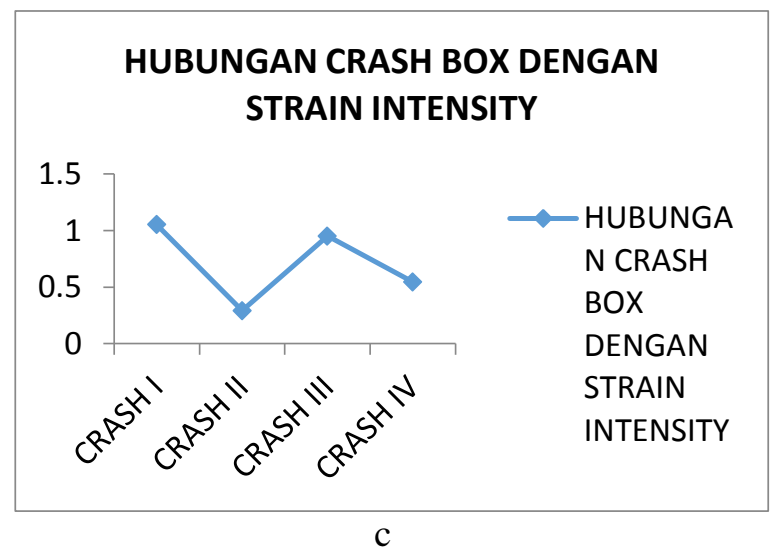

Gambar 10. a, b, c, Grafik Crash Box

Dari grafik diatas hubungan jenis crash box dengan energy regangan yang dihasilkan dari uji impak simulasi ansys didapatkan nilai energy regangan pada crash box I sebesar 1,053 $\mathrm{m}$ dan pada crash box II cenderung menurun sebesar 0,29092 $\mathrm{m}$ hal ini disebabkan oleh perbedaan diameter dari kedua crash box, nilai energi regangan mengalami peningkatan dengan diameter crash box III sebesar 0,95142 m yang disebabkan oleh luas bidang kontak dari crash box dan pada crash box IV cenderung menurun kemampuan menyerap energi regangan. Sehingga crash box II dengan diameter silinder $85 \mathrm{~mm}$ kemampuan menyerap energi regangan paling kecil yaitu sebesar 0,29092 m dibandingkan dengan crash box I, III dan IV.

Kemampuan menyerap energi regangan dari crash box dan deformasi yang terjadi, adanya perbedaaan yang signifikan dari variasi diameter silinder dari ke empat jenis crash box dengan variasi diameter.

Hasil dari simulasi crash box sesudah terjadi deformasi ditampilkan pada gambar di bawah ini : 


\section{Nanang Tawaf, Asroni}

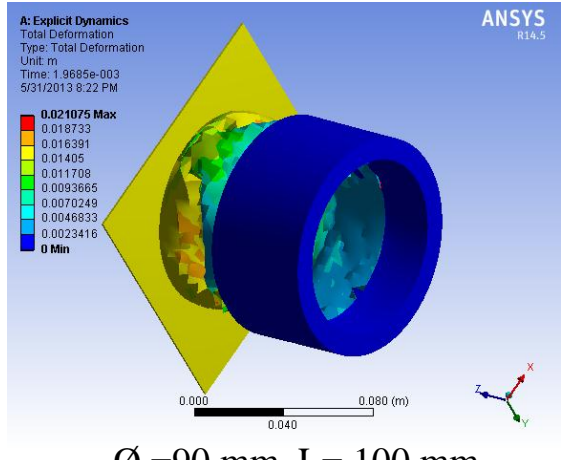

$\varnothing=90 \mathrm{~mm}, \mathrm{~L}=100 \mathrm{~mm}$

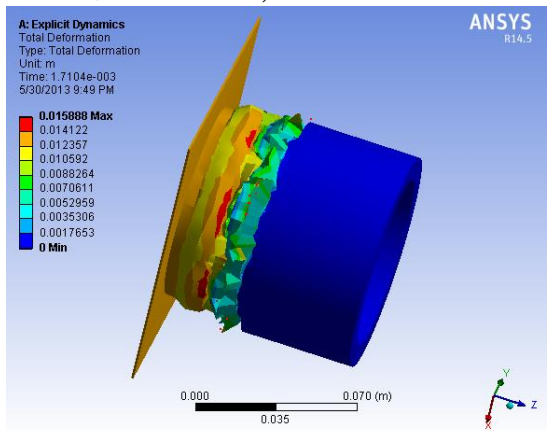

$\varnothing=85 \mathrm{~mm}, \mathrm{~L}=100 \mathrm{~mm}$

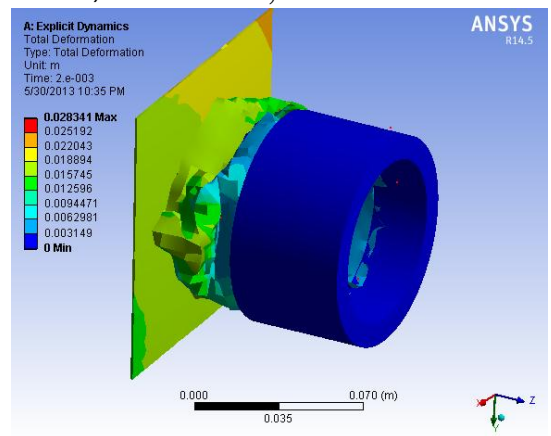

$\varnothing=80 \mathrm{~mm}, \mathrm{~L}=100 \mathrm{~mm}$

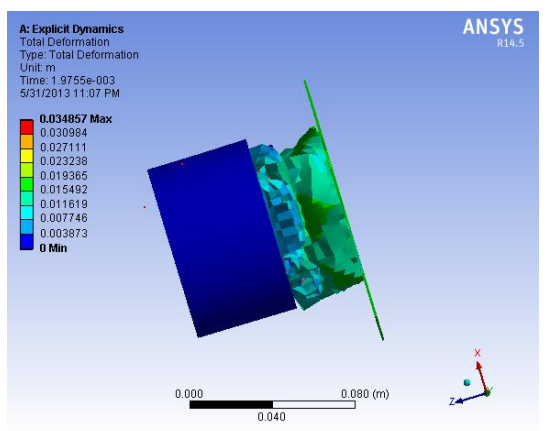

$\varnothing=75 \mathrm{~mm}, \mathrm{~L}=100 \mathrm{~mm}$

Gambar 11. simulasi crash box

\section{KESIMPULAN}

1. Dengan variasi diameter crash box maka deformasi yang terjadi semakin besar, yaitu crash box I diameter $90 \mathrm{~mm}$, crash box II diameter $85 \mathrm{~mm}$, crash box III diameter $80 \mathrm{~mm}$, crash box IV diameter $75 \mathrm{~mm}$, masing - masing memiliki deformasi sebesar $0.021075 \mathrm{~m}, 0.028341$ $\mathrm{m}, 0.028616 \mathrm{~m}$ dan $0.034857 \mathrm{~m}$.

2. Semakin berkurangnya rasio $(\mathrm{D} / \mathrm{L})$ maka efisiensi perpindahannya semakin kecil sehingga deformasi plastis yang dihasilkan makin besar pula sehingga penyerapan energinya makin maksimal dan efek deselerasi nya makin menurun, efisiensi gaya tabrak makin menurun dikarenakan perbandingan gaya puncak dan gaya ratarata semakin kecil akibat pemadatan atau compaction yang terjadi akibat tumbukan.

3. Semakin besar diameter crash box, maka luas permukaannya juga semakin besar sehingga momen inersia luasannya pun juga semakin besar, besarnya momen inersia luasan berpengaruh terhadap nilai beban kritis yang dihasilkan, semakin besar momen inersia luasannya maka beban kritis yang diperlukan untuk mendeformasi crash box juga semakin besar. Besar beban kritis sendiri berpengaruh terhadap gaya yang diterima oleh crash box semakin besar beban kritis maka gaya awal yang diterima crash box untuk mengalami buckling pada dinding juga semakin besar.

\section{DAFTAR PUSTAKA}

1. Gunawan, Dirgantara and Putra. 2010. Development of a Dropped Weight Impact Testing Machine. Indonesia.

2. Moaveni, Saeed. 1999. Finite Element Analysis Theory and Application with ANSYS. New Jersey : Prentice Hall.

3. Nakazawa, Tamura dan Yoshida. 2005. Develoment Of Crash-Box For Passenger Car With High Capability For Energy Absorption. Jepang.

4. Nentchev, A. 2002. Numerical Analysis and Simulation in Microelectronics by Vector Finite Elements. USA.

5. Robert D. Cook, David S. Malkus dan Michael E. Plesha. 1989. Concepts and Applications of Finite Element Analysis. Canada: Wiley.

6. Y. Nakasone and S. Yoshimoto, 2006. Engineering analysis with ansys software, Departement of Mecahnical engineering : Tokyo 